\title{
An Action Research Study of Promoting Teachers' Confidence and Competence in Teaching English Meaningfully
}

\author{
Eiman Nather \\ Riyadh Training Department in the Ministry of Education \\ Kingdom of Saudi Arabia
}

Received: February 21, 2021

Accepted: April 20, $2020 \quad$ Published: June 3, 2021

doi:10.5296/jet.v8i1.18336

URL: http://dx.doi.org/10.5296/jet.v8i1.18336

\begin{abstract}
This action research study investigates the introduction, implementation and evaluation of a training course-Meaningful Communication in English (MCE) - designed for English teachers at Saudi public schools. The course aims to promote the teachers' confidence and competence to use alternatives in classroom practices and develop an English communicative and interactive syllabus. Saudi public schools aim to educate students to use English in reallife communication. However, the current classroom practices do not meet these expectations. Despite having been taught English from Grade 4, most Saudi high school students graduate with low levels of understanding and competence when communicating in English. Saudi teachers and students are afraid of change because they are confused and suspicious about the functions and effectiveness of interactive classroom activities. This situation in schools demands the development of a training course based on communicative and interactive pedagogies and topics related to real life situations. The study is conducted in two cycles to investigate the training strategies and acquisition associated with MCE over 180 hours of training. Each cycle of MCE is based on the themes of the first three stages of research: theme 1- 'identifying the problem', theme 2- 'reviewing literature' and theme 3- 'developing a plan'. Upon the completion of MCE in each cycle, participant teachers were encouraged to conduct the following two stages 'implement the plan' and 'evaluate the outcomes' at their classrooms while providing remote supervision and support. The MCE training course differs from the traditional trainer-directed approach to introducing a learner-centered approach. Two hundred and forty-three English teachers contributed to this study and participated in observations, directed group discussions and surveys. The study found that MCE contributes positively to teachers' professional confidence and competence. The outcomes from this study will inform current practice and policy in the teaching and learning of English in Saudi Arabian training rooms as well as classrooms, and will contribute to creating an engaging, interactive and
\end{abstract}


learner-centered training courses for the future.

Keywords: Educational training courses, human resources, E-Learning, EFL Education, Saudi public schools, interactive activities.

\section{Introduction}

Saudi Arabia's Vision 2030 is a major transformation plan built around three themes: "a vibrant society, a thriving economy, and an ambitious nation" (Kingdom of Saudi Arabia Vision 2030, 2016). Considering the Saudi vision of development 2030 and the growth of English as the global language, it is increasingly important for the Kingdom of Saudi Arabia (KSA) to be fully engaged in the international community and for its young people to have an effective command of English. Communication in English will contribute to a better understanding developing between the West and the Arab world. Learning other languages presents an opportunity for Saudi's young generation to be exposed to the cultures of these languages.

Saudi public schools aim to educate school graduates to use English meaningfully in communication with others. However, the current speaking curriculum, teaching strategies and learning environments do not meet these expectations (Al-Seghayer,2011). Large numbers of Saudi high school students graduate with little knowledge of English.

The Saudi Ministry of Education (MoE) (2005a) stresses the need for qualitative learning experiences to keep up with scientific progress, social and economic development and global changes. Educators relate student deficiencies in communicating in English to the students' negative attitudes towards learning English and the teaching methods and learning environment are considered inappropriate (Al-Seghayer, 2014). Teachers are aware that students are reluctant participants in English speaking classes (pilot study). My 20-year experience as a public intermediate school-teacher gave me firsthand insights into language-learning issues, such as students' reluctance, avoidance, resistance and embarrassment related to speaking English. Finally, parents have expressed concern that the current strategies for teaching and learning English are inadequate and do not increase student confidence to communicate in English (Al-Abdallay, 2010; Al-Bluey, 2016).

This situation in education demands the exploration and development of English training course that incorporate communicative and interactive training strategies that depends on a learner-centered approach to encourage English teachers to use alternatives in classroom practices.

\section{CONTEXT}

Until the academic year for 2002/2003, English was a required subject for Grades 7 to 12 for both boys' and girls' schools. The English curriculum was introduced at the upper elementary level at the beginning of the academic year 2003/2004. It was introduced because the low English proficiency level of Saudi students was believed to be the result of limited English instruction prior to the intermediate and secondary levels. Since then, Saudi students have learnt English as a compulsory foreign language in Grade 4 and continue to do so throughout their schooling (Saudi MoE, 2005b). Saudi students are required to study English for a total of 
nine years.

At all stages of schooling, the majority public-school students undertake four English classes per week, each lasting 45 minutes. In other words, students have English classes for three hours each week. Since 2015, students have 170 days of learning English each year. By the time a student has reached Grade 12, 3825 hours of English instruction have been completed (personal experience).

\section{Education Reform}

According to Al-Hazmi (2003), Saudi English-classrooms over the four decades before 2000, can be described as non-systematic since it was with no defined objectives. In 2004, King Abdullah's project Tatweer, was introduced with the aim of promoting significant quality improvement in education in general and English language education, especially in terms of:

- Training and improving the qualifications of schools' leaders and teachers.

- Developing curricula and establishing extra-curricular activities.

- Improving the school environment.

- Activating the role of the student in classroom.

- Integrating computer-based instruction in classrooms (Tatweer, 2010).

Through Tatweer, the MoE has embraced new perspectives on educational policy and has replaced educational goals, curricula, contents and methods with creative new approaches that are appropriate for the twenty-first century.

In 2015, His Royal Highness, Prince Mohammad Ben Salman announced the KSA vison 2030; thus, the government does tremendous effort aiming at undertaking a significant and comprehensive reform in education to produce educated people qualified for labor market and ready to continue with educational development to compete with their international counterparts. Yet, some significant challenges face the Saudi educational system and have caused the inadequacies of the present education system to prepare students for a global future.

\section{Challenges of Education in the KSA}

The challenges facing the educational system in the KSA include lack of consistency in administrative regulations, lack of qualitative curricula, lack of flexible schedule, lack of qualified teachers, lack of motivated educational environment, lack of positive attitudes towards the educational profession, and lack of change acceptance.

\section{a. Lack of consistency in administrative regulations}

Since 2014 up to date, the Saudi ministry of education has witnessed massive development with hiring four ministers; each one of them came with different visions for development. This has caused huge confusion in the educational process. For example, some of these four minsters had followed bureaucracy in education. Consequently, supervisors and teachers were assigned with more administrative works which distracted them from focusing on the educational 
process. Moreover, in 2016, the ministry of general education and the ministry of higher education merged under the name of the ministry of education. Changing four ministers in a short period of time and connecting the two ministries together have put huge pressure on employees in the ministry to adapt with this situation, while still planning to raise the standards of education and ensure the improvement of its outcomes (Personal experience).

\section{b. Lack of the qualitative curricula}

The first challenge facing the educational system in the KSA is the lack of the qualitative curricula to prepare students for a global future by promoting the students' skills in effective communication and critical thinking. The English Foreign Language (EFL) curriculum in Saudi public schools has undergone several changes. With each successive curriculum, the government has sought to improve the quality of FL education in terms of interest, content and relevance and the competency of Saudi EFL learners (Al-Seghayer, 2014).

KSA education is dominated by a textbook-driven curriculum that prescribes what is taught and how it is taught. It is mandatory for all schools at all levels to use the same textbooks, methods of instruction, evaluation techniques and educational policy. Additionally, all students of the same age start from the same point (personal experience). This strategy limits teachers' and students' creativity and focuses on the mastery of content.

The curriculum in place in most schools when this study was conducted was Smart Class for primary schools, Full Blast for intermediate schools and Travelers for Secondary schools. There is a textbook for each semester consisting of four to five units. Each lesson occupies two pages and is taught over two days - that is, teachers work with the materials of each topic as a unit for eight classes.

In general, Saudi curriculum decision makers lack immediate contact with teachers and classroom practices; thus, they rely heavily on supervisors' reports. These reports and research studies often reflect an inaccurate picture of classroom settings because supervisors observe only a few classes and do not regularly communicate with students. Teachers are encouraged to submit recommendations to the Saudi MoE, especially in terms of textbooks. However, these recommendations generally are not considered because English teachers lack relevant qualifications and academic knowledge about foreign language education (personal experience). The MoE determines that the role of the teacher is to transmit the content of the textbook to students. Consequently, there is compatibility in the educational outputs with labor market requirements.

\section{c. Lack of flexible schedule}

Teaching of English in KSA is centralized and controlled by the MoE (Al-Seghayer,2011). English teachers at each grade level are required to adhere to identical syllabus guidelines and deadlines. A textbook for each grade contains as many lessons as teaching weeks; therefore, there is no consideration for remedial, supplementary or enriching activities. For example, a lesson of 45 minutes of English generally consists of activities to practice the four skills of reading, listening, speaking and writing. Teachers are expected to complete the materials 
prescribed for each lesson, and the homework from the previous lesson is checked. Teachers must complete the curriculum on time, irrespective of whether the lessons' objectives have been achieved by students. As a result of this rigid curriculum and prescriptive pedagogy, the competency of students receives insufficient attention, including their competency in speaking English.

\section{d. Lack of qualified teachers}

English Foreign Language (EFL) teacher preparation programs in the KSA before 2000 was non-systematic and inadequate. Relying on unqualified and inexperienced English teachers has long been a problem in the KSA.

English teachers graduate with a bachelor degree from the English departments of colleges of education in universities. They enrol in an intensive program in English for a semester, then join a four-year academic English program. They study a number of courses, such as English linguistics, phonology, morphology and syntax, teaching methodology, educational psychology, sociology of education, evaluation, school administration and curriculum studies (Al-Hazmi, 2003). Finally, upon graduation, they practice teaching for a semester in public schools under the supervision of an academic advisor. Yet, after graduating from universities, most English teachers lack subject knowledge, language proficiency and competence in FL teaching methodology.

Many teachers lack essential English skills to teach the language (Saudi MoHE, 2010). In addition, as non-native speakers, Saudi teachers face the challenges of teaching pronunciation, overcoming the perception of inferiority, and seeking to choose authentic oral resources (Bailey et al, 2008). Moreover, in-service education programs for teachers are conducted on a limited scale via the local education departments across the Kingdom (Al-Qurashi, 2002).

Al Qahtani (2013) suggested a systematic approach to pre-service and in-service education for improving EFL teacher education programs. The training received during teacher candidates' undergraduate studies is of particularly great importance since teachers obtain most of their qualifications regarding their profession in this period. That is why teacher training programs should equip candidate teachers with the subject knowledge, skills, abilities, and attitudes necessary for them to become creative teachers.

\section{e. Lack of a motivated educational environment}

The lack of a motivated educational environment to encourage innovation and creativity is another challenge facing the educational system in the KSA (Al-Sunbul et al, 2001). Most Saudi classroom learning adheres to a traditional teaching and learning model, in which the student is the receiver of information and the teacher is the imparter of knowledge. The physical appearance of classrooms is a traditional one, with desks arranged in parallel rows in front of the teacher's desk (personal experience).

Furthermore, the large classes which include 40 -50 students and the subsequent greater demands placed on the current education system are stressful challenge facing the Saudi education system (Saudi MoE, 2005a). Significant to education in the KSA is the fact that 
$41.9 \%$ of the population in 2010 was in the age range of zero to 15 years (Al-Sha lan, 2010), and this percentage has increased in the following years. The number of schools, teachers and students is expected to increase in the future (Saudi MoE, 2013). The annual increase in the number of students gives the KSA a high ratio of students to teachers. Providing more schools and qualified teachers is a considerable challenge facing the MoE.

\section{f. Lack of motivated students}

Most Saudi students usually do not pay serious attention to learning English because there is no immediate application in society. Moreover, teachers use extrinsic motivation - that is, they grant grades to encourage students to learn English. In other words, intrinsic motivation is nonexistent. Consequently, students tend to devote little effort to achieving the minimal grade required to pass; they memorize vocabulary, grammars and passages of composition because that is what is required for their final exams (personal experience).

\section{g. Lack of positive attitudes towards the educational profession}

The negative stereotyping attitudes towards the educational profession held by the society is one of the challenges facing the educational system in the KSA. Similar to any profession, teaching can be more effective when individuals possess positive affective characteristics (Ahmad \& Sahak, 2009). Teachers with positive attitudes towards the teaching profession are likely to be more successful in their profession.

Various studies have shown a positive correlation between teacher attitudes and teacher effectiveness and productivity and success in the profession (Stronge, 2007). Teacher attitudes also directly affect school climate. Employees with positive attitudes towards their profession have higher job satisfaction and are more committed to their profession (Sager, 2004). Attitude towards the teaching profession is a pivotal quality that determines a teacher's willingness to develop and grow as a professional. The more positive and enthusiastic teachers are about teaching, the more likely their students will be enthusiastic about learning.

\section{h. Lack of change acceptance}

Attempts have been made to change the Saudi education from a traditional environment to be more interactive; however, such attempts have not been particularly successful because Saudi teachers and students are afraid of change; they are confused and suspicious about the functions and effectiveness of interactive classroom activities (Pilot study). Teachers lack knowledge about alternative methods of teaching as they have no training or experience. Moreover, they lack the confidence and knowledge to generate independent practices (Dukhayil, 2002).

According to Arani (2004), the education systems in the Gulf Countries, including KSA experience great difficulties in coping with these complex challenges. He argued that even if reforms are planned, they are not always implemented or managed properly. In addition, reforms of structures, curricula, programs, content and methods, which are being executed, very often meet with a great deal of resistance from parents, teachers' unions and sometimes even from learners themselves. 
Reviewing the constraints of Saudi education, the bottom line is the gap between current educational strategies and future comprehensive plans is a challenge facing the Saudi education (Saudi MoHE, 2010).

Meeting the objectives of the Saudi vision 2030 and overcoming the challenges points to a crucial need for a major educational reform by enhancing new perspectives on educational policy and replacing educational goals, curricula, contents and methods with creative new approaches suitable with the development of the $21^{\text {st }}$ century (Saudi MoE, 2013). Subsequently, teaching and learning strategies should be changed from a focus on education and teaching, to a focus on learning; from students as passive recipients of information and services, to students as critical thinkers and life-long learners (Akkary-Karami, 2014).

Addressing the constraints of education, particularly teaching English in Saudi classrooms and to improve teaching and learning opportunities for teachers and students, a training courseMeaningful Communication in English (MCE) - was developed for English teachers. MCE considers the learning environment; resources; effective strategies for teaching English; and ways to encourage greater engagement, confidence and interaction in English classrooms to enable teachers to be competent and confident to encourage meaningful communication in English in their classrooms.

A growing body of research has been conducted to investigate the factors that promote teachers' competence in teaching English (Reid \& Walker, 2012). However, to date, there has been no research study conducted to promote English teachers' confidence and competence in the Saudi context.

In the context of Saudi education and human resources innovations, this study is groundbreaking. Few systematic training courses have been introduced for English teachers. MCE was designed specifically to meet the Saudi public-school teachers' and students' needs. Moreover, training in the traditional Western sense is a relatively new consideration in the KSA. A new approach that emphasizes a two-way interaction between supervisors and teachers is adopted. This course introduces practical solutions to assist hesitant teachers to overcome their reluctance to use alternatives in classroom practices taking into consideration the constraints of Saudi classroom such as the lack of the qualitative curricula, flexible schedule, qualified teachers, the motivated educational environment, the society's positive attitudes towards the educational profession, large classes and fear of change.

The findings from this research can lead to improved classroom practices, particularly in EFL education in Saudi classrooms. This course considers how the classroom social environment influences trainer and learners' engagement and performance. It is anticipated that generating a rich description of a range of activities that can be used in the Saudi context to encourage confidence and competence in communication will provide a useful resource for stakeholders, supervisors and teachers of English. Furthermore, this will contribute to improving Saudi students' learning of English in public schools, and confidence in speaking English.

\section{METHODOLOGY}


This action research study examined the introduction and implementation of the innovative training course, Meaningful Communication in English (MCE), designed for English teachers at Saudi public schools. Action research involves the researcher working alongside trainees (English teachers) to bring about change in the types of activities used to improve the effectiveness of Saudi English training courses. Two hundred and forty-three English teachers contributed to this study; they include 49 primary-school teachers, 99 intermediate-school teachers and 94 secondary-school teachers.

In the process of carrying out action research, the training course took place at the main training department and the seven female centers located in all regions of Riyadh over the duration of two semesters (2018/2019). MCE was implemented and evaluated for a total of 45 days. The trainees of each center had three days of training; each day included 4 training hours. A total of 12 hours of training had been conducted in each center. Approximately, from 12 to 25 trainees participated in MCE in each center. MCE was developed and implemented for 180 hours of training to promote English teachers' confidence to find alternatives and develop a syllabus that embraces communicative and interactive pedagogies.

The focus of the study was to investigate the effect of the interactive-based activities of MCE on English teachers' willingness to plan and employ communicative classroom activities to engage their students in classroom. Data sources included observations, directed group discussions and surveys. The data were analyzed using a grounded theory approach. The study systematically examined the development of the MCE course, its training-room implementation, and its effect on the trainees as they engaged in MCE activities.

Action research is employed in this qualitative study; in particular the definition of Birks and Mills (2011) which based on the idea that action research is the process of systematic collection and analysis of data in order to make changes and improvements or solve problems. In addition, it is the way groups of people can organize the conditions under which they can learn from their own experiences and make these experiences accessible to others. Action research allocated the study because it provides a means of generating and sustaining improvements in teaching and learning in KSA classrooms. Moreover, it provides opportunities to reflect on and assess current practices to explore new ideas, methods and materials and to assess the success/lack of success surrounding initiatives. Finally, it enables the researcher to share feedback and seek the opinions of stakeholders and leads to informed decision making.

\section{Participants}

The target trainees are the English teachers at primary, intermediate and secondary public schools in Riyadh. The trainees in this action research study included 243 Saudi female English teachers. These trainees participated in this training course because they seek professional development.

\section{Participant Researcher}

As a participant researcher in both cycles, I introduced the activities of MCE while collecting data through observing trainees' reactions and evaluating their progress, conducting interviews 
and collecting artifacts. Prior to the study, I had 15 years of teaching experience at a Saudi government school and five years of experience in training-supervision. My Master's Degree in TESOL (Teaching English to Speakers of Other Languages) and my $\mathrm{PhD}$ degree in developing English curriculums and teaching strategies gave me a sound research base, expertise, credibility and the confidence to conduct this study.

\section{Trainees}

A total of 243 trainees were involved in this study, 189 of whom had bachelor's degrees and 54 of whom had master's degrees. The trainees observed me introducing the activities of MCE, had ongoing discussions and evaluated the progress and effectiveness of activities through directed group discussions and completed reflections at the conclusion of the training course MCE.

- Fifty-eight trainees had from 1 to 5 years of teaching experience and did not have academic or practical experience in teaching before being hired. Most of these novice teachers were enthusiastic and creative in planning extra activities to encourage students to speak English by planning and teaching lessons of revision for the class at the middle and end of the semester.

- A hundred and twenty trainees had from 6 to 15 years of professional experience. They were enthusiastic and creative who provided training activities to encourage other teachers to teach English creatively. Most of these trainees were competent in using technology. Some of them provided ongoing support for other trainees on the use of Microsoft programs.

- Sixty-five trainees had from 16 to 25 years of professional experience. Some of these trainees, particularly the ones who had more than 20 years of experience teaching English were bored by the routine of teaching and wanted to upgrade to vice-principal or retire.

These trainees volunteered to participate in this study because they were aware that the present spoken curriculum and teaching methods were producing neither competence nor confidence in their students to communicate meaningfully in English. Most of these trainees lacked confidence in classroom instruction; however, they were very enthusiastic to develop their strategies for teaching.

\section{Study Site}

The study took place at the main training department (Ar-Rabwah) and the seven training centers that caters for females. The principal was highly motivated and supportive of potential improvements in the quality of education in the KSA. The training department and centers equipped with the facilities, educational resources and technology required for MCE.

The main female department of training and scholarship located in the eastern region of Riyadh, particularly, in Ar-Rabwah district. It is surrounded by a two-meter wall and has two yardsone at the entrance and one in an inner yard. The inner yard is surrounded by a building 
consisting of two floors, and all training rooms face this yard. This design is practical and allows easy mobility and communication. The ground floor houses mainly the principal, principal secretaries and many rooms for staff of Scholarship. The ground floor also includes 3 rooms for training. The two other floors include the trainers' offices and the majority of the training rooms. The library is on the second floor. The educational resources in this library are made available for trainers, and included books, periodicals, newspapers and brochures. Nonprint resources were also used, such as audio and visual resources (photographs and maps). The library was equipped with shelves, tables and chairs.

The training rooms in Ar-Rabwah training department was equipped with the facilities and technology required for MCE. All the training rooms contained space for group work and have good air conditioning system and many windows that allow light and fresh air to enter. The physical appearance of the training rooms encourages interactive communication; desks are arranged in groups.

Making training available to all female employees of MoE, seven training centers were established in different regions of Riyadh depending on to the intensity of the population. These training centers include the central region center, the eastern region centers (Ar-Rawabi district and An-Nahdah district), the western region center, the northern region center and the southern region centers (Al-Badiyah district and Ashefa district).

Apart from the central region training center, which is connected to a department of MoE, all the training centers buildings are connected to public schools. These training centers occupied part of the second floor in these buildings. Consequently, the training rooms in these centers are smaller than the rooms in Ar-Rabwah center. These centers were equipped with old facilities and technology. The rooms of some of these training centers have bad air conditioning system and some of the windows are locked. Attempts have been made to improve these training centers; however, the budget devoted for these centers is the obstacle.

\section{Research Design}

The six steps of research design developed by Corbin and Strauss (2008) were applied in this study and are explained below.

\section{Step 1: Problem Identification}

The study problem was Saudi teachers' lack of competence and confidence to master communicative and interactive activities in English classroom. A preliminary pilot study was conducted to investigate this initial problem, and to seek ways to improve the curriculum opportunities for Saudi students in English-speaking classrooms. Additionally, a case study was conducted to examines students' responses to an integrated program designed to promote their confidence in speaking English.

\section{Step 2: Preliminary Investigation}

The preliminary investigation involved a pilot study conducted in 2007 in two public schools in Riyadh (Nather, 2020). Ninety students from Grades 7, 8 and 9 and their six teachers were 


\section{Macrothink

surveyed. The study found that most Saudi students admitted to lacking confidence in speaking English. Most teachers and students were dissatisfied with the way English was taught and learnt in Saudi classrooms and did not like the English textbook. They preferred learning how to use the language, rather than learning about the language. This result agrees with the findings of Al-Seghayer (2014). The findings suggest the need for more opportunities for English teachers to communicate with colleagues via authentic resources and interesting activities in which teachers can share experiences and talk about challenges in classrooms and suggest solutions.

These results suggested the need for more opportunities to practice speaking in classrooms via authentic resources and interesting activities in which students can talk about themselves and their hobbies, tell real stories, watch English films and role-play.

Accordingly, in 2014, a case study was conducted by Nather (2017) to examines students' responses to an integrated program "Let's Speak English (LSE)" designed to promote students' confidence in speaking English. The study introduces new syllabus to a class of Year 7 students for one semester. The syllabus is based on four activities including "My News", "Islamic Chants", "Stories in English" and "Videos in English". The syllabus encourages moving from a teacher-centred paradigm to a Learner-Centred paradigm by using a variety of strategies and teaching differently. Twenty-one teachers, four supervisors and 28 students contributed to this study and participated in observations, interviews and surveys. This study found that LSE contributes positively to students' linguistic confidence and competence. The factors found to contribute to students' increased confidence and competence included increased opportunities to participate in group activities and speak English in front of peers, connecting learning to real-life experiences and the Islamic religion, authentic activities, and a supportive learning environment.

The outcomes from both studies informed current practice and policy in the teaching and learning of English in Saudi Arabian classrooms, and will contribute to creating an engaging, interactive and learner-centred syllabus for the future.

Thus, MCE was designed to include the findings of the pilot study and the case study. MCE was designed to promote English teachers' confidence to find alternatives and develop a syllabus that embraces communicative and interactive pedagogies.

\section{Step 3: Hypothesis}

The following questions arose from the two earlier studies:

1. What is MCE?

2. Does MCE build confidence and increase the participation of trainees? If so, how does it do this?

3. What training and learning strategies of MCE contributed to the improvement of English training courses?

4. What is the role of the MCE trainer in English training courses? 


\section{Step 4: Intervention}

The training course MCE encourages a learner-centered approach based on new content and new pedagogies that are different to those of the traditional trainer-directed approach. MCE is designed, built and developed in a systematic manner to achieve the desired objectives. It includes 29 interactive activities based on the themes of the first three stages of research. Topics of Day 1 include identifying the problem that hinders public school students to communicate meaningfully in English by discussing the context of EFL education and its challenges and discussing the possibilities of change. Topics of Day 2 focus on reviewing EFL literature. Finally, topics of Day 3 emphasis putting the ideas of MCE in practice and developing a syllabus that encourages communicative and interactive pedagogies taking advantage of the trainer's and trainees' professional experiences in this field. Upon the completion of MCE, participant teachers were encouraged to conduct the following two stages: 'implement the plan' and 'evaluate the outcomes' at their classrooms.

These themes considered the need for a stimulating training environment, positive atmosphere, collaboration, interactive training, authentic activities and learner-centered approach.

\section{Step 5: Evaluation}

The participant researcher and trainees evaluated the activities, resources, training environment and trainer's role during the development and implementation stages of MCE.

\section{Step 6: Dissemination}

The results of this study were disseminated to stakeholders and educators. The Department of Training and Scholarships in Riyadh received a final copy of the study. Feedback from the MoE was sought throughout the development and implementation phases of MCE.

\section{Study Cycles}

Inspired by the ideas of Ary et al (2010), this study included two cycles; each cycle involved five steps, namely: plan, act, observe, reflect and revise (Figure 1). In this study, Cycle One was in Semester 2 of the school year 2017/2018 and Cycle Two was in Semester 1 of the school year 2018/2019. As Stringer (2007) stated, devoting sufficient time for a study enables the researcher to achieve a deep understanding of a context and the reasons that stand behind learners' actions in a setting. 


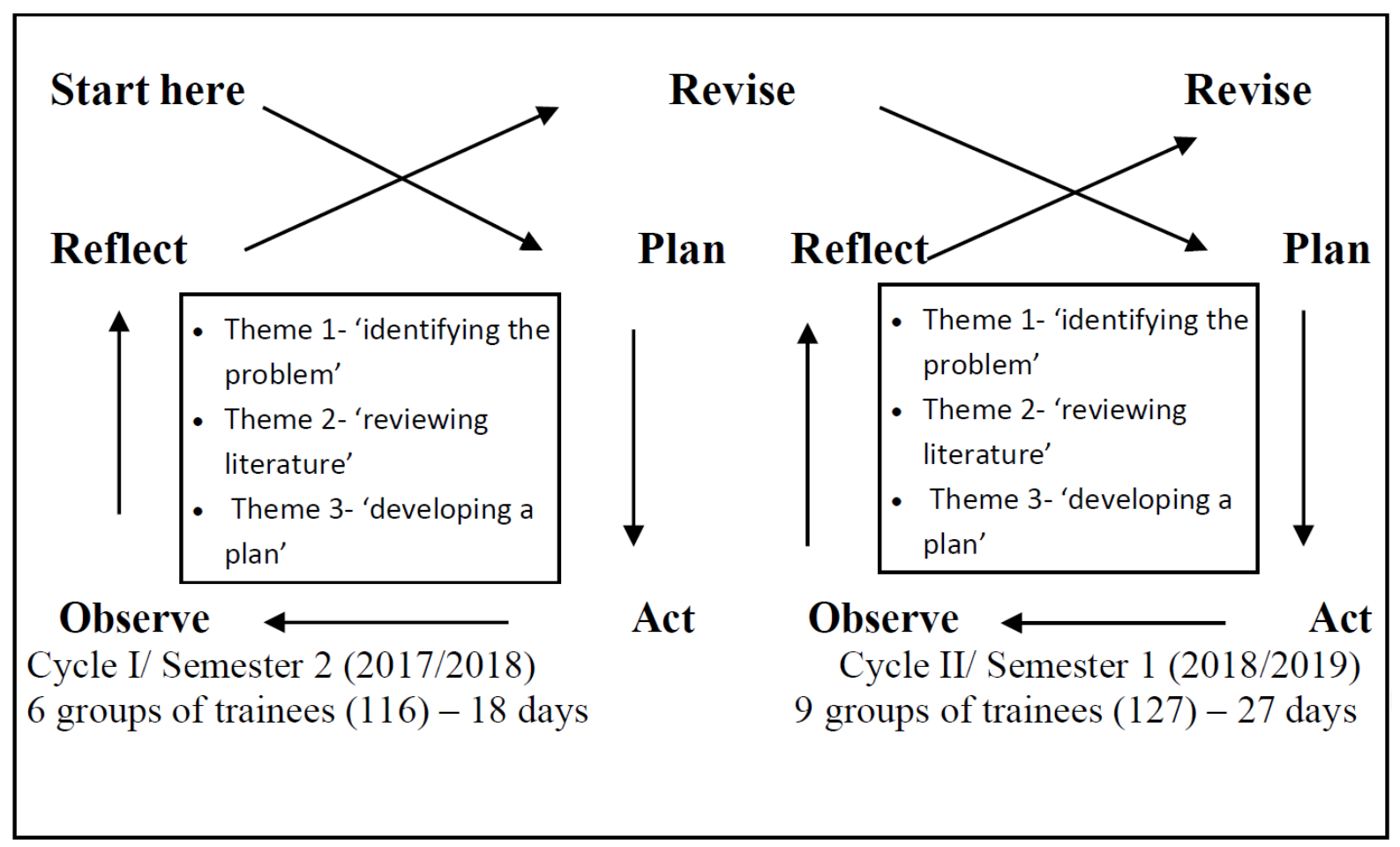

Figure 1: Cycles of the action research

Cycle One involved introducing the training course MCE to six groups of trainees for 18 days. One hundred and sixteen trainees were engaged in this cycle. Trainees in MCE worked on 29 interactive activities for three days in each of the six training centers; namely, the central region center, Ar-Rawabi center and An-Nahdah center in the eastern region, the main department of training (Ar-Rabwah), the western region center, and Al-Badiyah center in the southern region of Riyadh. After the collection and analysis of data, activities and the training approach were revised to improve the course for Cycle Two.

In Cycle Two, nine groups consisting of 127 trainees worked with these 29 interactive activities after they had been developed to meet the trainees' needs. In total the duration of Cycle 2 was 27 days. Each group participated for three days in the following training centers in order: AnNahdah center, the northern region center, the central region center, An-Nahdah center, ArRabwah training department, Ar-Rabwah center, Al-Badiyah center, Ashefa center and the western region center in Riyadh.

\section{Data Collection}

Data sources included observations, directed group discussions and artefacts that included field notes, samples of trainees' work and surveys. The study systematically examined the development of the MCE course, its implementation, and its effect on the trainees as they engaged with its activities. Over 180 hours of data collection in both cycles, the analysis was ongoing-I was continually searching for answers to the study's questions. In total, two hundred and forty-three trainees participated in both cycles of this study.

\section{Observation}


Direct observation happened in the training sessions and allowed me to witness events as they occurred and obtain important non-verbal evidence. Direct observations confirmed the data collected from directed group discussions and surveys. Over 180 hours, I trained and observed the implementation of MCE. The observations focused on everything that occurred in the training sessions. Data were recorded as field notes.

\section{Directed group discussions}

During the 180 hours of the training course MCE, directed group discussions were conducted with 243 trainees. These discussions allowed the trainee to share their insights to their professional experiences in FLE and helped develop a deeper understanding of their experiences of teaching English. The reflections of the directed group discussions were recorded as field notes after each session. This strategy allowed me to examine the recommendations in terms of the resources, trainer's role and attitudes in classroom management.

The directed group discussions were conducted with trainees before, during and after the implementation of MCE, the trainees participated in 15 directed group discussions. These discussions identified strengths and weakness in the trainer's methods of training that led to recommendations in terms of resources, activities, trainer's roles and classroom management and changes in the training environment. The implication of these recommendations was discussed with participant trainees. Ongoing follow-up questions to trainee were conducted for clarification, building and refining theories, and following up.

\section{Artefact}

Throughout the study, a variety of artefacts were collected, including field notes, samples of trainees' work and surveys.

\section{a. Field notes}

The field notes recorded everything and anything that occurred in MCE. The field notes provided a running commentary on factors that contributed to effective resources, activities and strategies of training. The field notes were recorded on a regular basis following every training session. Informal problem-solving discussions with trainee were recorded as field notes.

\section{b. Samples of trainees' work}

During the 180 hours of MCE, 29 activities were completed and trainees' work samples were collected. These samples included drawings, writing, thinking maps, personal reflections and related resources. They were collected at the end of each activity to judge the trainees' responses to MCE and their learning outcomes.

\section{c. Survey}

Five surveys were completed with 243 trainees at the beginning and end of MCE. The participant trainees provided a written response to questions designed to elicit information 
about MCE. Surveys were conducted with trainee to reflect on the course activities and knowledge and the trainer's role in achieving the aim of MCE. These surveys are as follow:

1. KWL Survey was completed by trainee at the beginning and end of MCE to assess trainees' knowledge before and after the implementation of MCE. Trainee wrote what they knew and would like to know about meaningful communication in English at the beginning of MCE while they reflected on what they have learned about meaningful communication in English upon the completion of MCE.

2. Five-minute Survey was conducted by trainee during implementing MCE; the trainees' needs and interests were identified. The related topics of literature reviews were written in four separate papers. These papers were put on each wall of the training hall. Trainee moved around and tick the most useful topics according to their needs. The most selected topics were the focus of the discussions in Day 2.

3. Trainees' Evaluations of MCE Survey were completed at the conclusion of the training course. This survey was conducted by the Department of Training in Riyadh to assess the trainees' satisfaction with the topics of MCE, the trainer's role, and the training environment.

4. Trainees' Perceptions Survey were completed by trainees upon completing MCE training course. Open-ended questions were used to collect data about the trainees' perceptions regarding the advantages and disadvantages of MCE in relation to achieving its aim. Trainees wrote their reflections on sticky notes and hanged it on the board.

5. Trainees' Recommendation Survey was completed by trainees upon completing MCE training course. Trainee wrote some recommendations for MoE to improve the EFL education. They chose to write their recommendations in Arabic.

\section{Data Analysis}

A grounded theory approach was used as a systematic way to analyse data (Charmaz, 2006). The data were read and re-read to discover codes, concepts and categories to explain the benefits and shortcomings of MCE (Lichtman, 2010). The analysis was ongoing while data collection - I was continually searching for relationships between concepts. Generating patterns and links, the aim was to create a theory that was grounded in this unique setting that has been largely unexplored by researchers. The theory shed light on the effect of the MCE and ways to improve KSA participant teachers' confidence and competence to teach English.

\section{CYCLE 1 - FINDINGS AND DISCUSSIONS}

The training course-Meaningful Communication in English (MCE) was designed to encourage and promote English teachers' confidence and competence in teaching English meaningfully. In this section, the perspectives of the trainer (training supervisor) and trainees (English teachers) are explored in relation to the implementation of the training course MCE. The issues and challenges that affect Saudi teachers' confidence and competence in teaching 


\section{Macrothink}

English are also identified.

\section{Growing Confidence}

Results of the directed group discussions in Day 1 of MCE suggested that only nine trainees felt confident teaching independently with some gaudiness of the textbook, while a hundred and seven trainees admitted lacking confidence to use new ideas in classroom practices because of the rigid schedule and the strictness of supervisors regarding following the prescribed plan.

Based on the observations, directed group discussions and surveys, it was apparent that the trainees' confidence improved, and they showed increased willingness to participate and share creative ideas. The trainees' enjoyment increased, while their anxiety decreased.

Reviewing the trainees' reflections in the first day of training - the trainees described designing activities different from the textbook as a 'difficult task' (T5). The trainees were 'nervous' (Ts $5,8)$ and 'hesitant' (T18). In the third day of training, according to directed group discussions and the survey, the trainees described designing activities different from the textbook as 'easier' (Ts 9, 3) and 'interesting' (T98). The trainees felt 'happy' (Ts 2, 16), 'excited' (Ts11, 25), 'confident' (Ts20, 91) and 'competent' (Ts18, 83).

In Day 2, it appeared that selecting more challenging activities to be used in training rooms increased the trainees' confidence and the sense of responsibility. Trainee 15 explained, 'The MCE activities are interesting and challenging as well. They are well planned'.

When designing classroom activities in Day 3, the trainees moved from following the textbook activities in classroom practices to creating more exciting and creative tasks based on students' needs. As Trainee 46 reflected, 'I am happy and excited working with my colleagues to plan interesting classroom activities. I am very confident now to plan new activities and my students will be happy too'.

Upon the completion of Day 3, I shared my experience in designing an interactive syllabus with the trainees who responded positively. For example, Trainee 1 stated, 'I like the idea of these activities and I am sure my students will like them too because they are new and motivating'. Trainees 17, 32, 54, 78 and 108 stated, 'The trainer's experience in teaching differently is very inspiring'.

\section{Developing Competence}

Upon the completion of MCE, the trainees' perceptions survey results suggested that all trainees were interested in MCE; fifty-six trainees were sure that MCE helped them develop their competence in teaching English. Trainee 55 reflected, 'I like the practicality of the training course; it is rich with real examples' (D3). Trainee 81 confirmed this, 'I like the course topics since they meet my professional needs and expectations' (D3).

On the other hand, the trainees were afraid of change. Traditionally, Saudi teachers have the central role in teacher-centered classrooms and, consequently - as observed during MCE - the trainees' initial responses to the idea of employing learner-centered activities in their classrooms that required collaboration and increased interaction was of fear. Trainee 4 stated, 


\section{Mll Macrothink}

Journal of Education and Training

ISSN 2330-9709

2021, Vol.8, No.1

'Doing new activities when teaching English is scary.' Some trainees rejected the idea of teaching differently. Trainee 7 reflected, 'I do not think we can teach differently; my supervisor would grade me down'. Through the variety of activities presented in MCE, the trainees had opportunities - with the support of the trainer and their colleagues - to face challenges and improve their participation.

Based on the survey results, observations, trainees' reflection and levels of participation, the trainees were aware of the improvement in their teaching competence and increased knowledge relating to subject topics. Based on the KWL Survey (pre- and post-), the trainees acknowledged their understanding to the language function, fluency-based and accuracy-based activities and teaching adolcent learners in large classes.

By the end of Day 1, most trainees reflected that they had increased confidence when discussing classroom difficulties:

Trainee 10: At the end of Day 1, the trainees are confident enough to discuss difficulties in classroom and suggest solutions.

Trainee 28: In Day 1, group discussions were interesting, and trainees had a lot of things to say!

The trainees were aware upon the completion of the activities of Day 2 that their teaching competence had developed to the point that they could talk about different pedagogies. For example, Trainee 58 reflected, 'After reviewing literature in Day 2, I know more about teaching methods. Therefore, I am more confident now to teach differently'.

In Day 3, the trainees' teaching competence increased, as did their understanding of specific topics related to communicative interactive teaching strategies such as task-based language teaching and community language teaching. According to their reflections and observation schedules, the trainees were able to plan, discuss and construct new activities based on their students' needs. Trainee 40 reflected, 'I discussed with my group the possibility of using community language teaching'.

\section{Factors Contributing to the Improvement of Trainees' Confidence in Cycle 1}

The trainer and trainees identified some factors that contributed to the trainees' improvement of teaching English. These factors increased the trainees' confidence and competence to teach English creatively, and - as noted by most trainees - they increased their willingness to find alternatives in classroom practices and teach differently. These factors were a stimulating training environment, a positive atmosphere, collaboration, authentic activities and interactive training, and a learner-centered approach.

\section{Changes for Cycle 2}

A stimulating training environment that included technology and comfortable and enough space for interactive learning environment proved essential to the success of the learning process in Cycle 1. However, some trainees had negative attitudes in some of the training centers, particularly Ashefa and the western and northern training centers. 
Making accommodation in Cycle 2, these training centers have been moved to new modern style buildings in 2019. Based on the trainees' perception survey, trainees had positive attitudes towards the training environment in these centers. The physical surroundings of the training rooms in these new buildings were seen as comfortable and equipped with updated devises of technology.

The positive training atmosphere was further enhanced in Cycle 2 by introducing group competition in a safe and comfortable training environment. Although, the disadvantages of making competition in learning setting, most trainees ask for group competition in Cycle 2. Meeting their needs, competitive activities were integrated in Day 2.

To further encourage fluency in group discussions in Cycle 2, trainees were allowed to substitute Arabic words for any English words they did not know. Allowing the usage of Arabic to discuss classroom difficulties in an English training course was criticized by some of my colleagues. Despite this criticism, since the message is the focus, asking trainees to share experiences using mother tongue language to talk within the allocated time motivated most trainees to participate enthusiastically in directed group discussions.

\section{CYCLE 2 - FINDINGS AND DISCUSSIONS}

The training course-Meaningful Communication in English (MCE) was designed to encourage and promote English teachers' confidence and competence in teaching English. In this section, the perspectives of the trainer (training supervisor) and trainees (English teachers) are explored in relation to the classroom implementation of the ideas of the training course MCE. The issues and challenges that affect Saudi teachers' confidence and competence in teaching English are also identified.

\section{Growing Confidence}

According to the results of the trainees' directed group discussions upon the completion of Day 1,115 out of 127 said they lack the confidence and knowledge to generate independent practices. Accordingly, these trainees implement a superficial demonstration of communicative language teaching by encouraging students to imitate the textbook dialogues and do restricted pair and group work activities.

Reviewing the trainees' reflections in the first day of training - the trainees described designing activities different from the textbook as 'a strong fear' (T3). The trainees were 'afraid' (T2) and 'confused' (T56). In the third day of training, according to trainees' perception survey, the trainees described designing activities different from the textbook as 'encouraging' (Ts 25,3).

Based on observation and trainees' reflections in relation to confidence, it was apparent that the trainees' confidence increased in Day 2 as they participated to do challenging activities. The trainees' enjoyment increased when having confidence, while their anxiety decreased.

The results of the directed group discussions in Day 3, as trainees gained confidence, they started to experiment and take greater risks when planning to design creative interactive classroom activities. Trainee 69 sated, 'I am confident now to plan and employ communicative 
activities in classroom'.

When sharing my experience in designing interactive syllabus in Day 3, all trainees responded positively too. Trainee 2 stated, 'I used to give my students extra activities for speaking, but this course is well prepared and has a specific aim, which is promoting the students' confidence in speaking English'. Trainee 83 stated, 'Supporting the knowledge of MCE with real experience in classroom practices, particularly by the trainer is a smart idea to connect learning theories with real classroom practices. This builds our confidence in teaching English creatively to meet our students' needs'.

\section{Developing Competence}

Similar to Cycle 1, although most trainees showed positive attitudes to the training course MCE, they were worried and nervous about introducing learner-centered activities in their classrooms. Trainee 51 claimed, 'I am not sure if I would be able to apply these activities because I do not know how to start'. Later, when practicing MCE activities, trainees developed confidence as they had opportunities — with the support of the trainer and their colleagues - to face challenges and improve their participation.

The trainees' teaching competence in Cycle 2 was evident in their increased knowledge that was content specific and previously unfamiliar to most trainees. Based on the survey results, observations, trainees' reflection and levels of participation, the trainees were aware of their improvement in their teaching competence and increased knowledge relating to subject topics.

By the end of Day 1, most trainees reflected that they felt comfortable talking about their classroom practices as Trainee 3 stated, 'Topics of Day 1 developed positive social relationships among trainees as they discussed solutions to the common classroom' challenges'.

Upon the completion of the activities of Day 2 in Cycle 2, the trainees were competent enough to discuss the possibilities to use different pedagogies in their classrooms. For example, in Day 2, Trainee 68 reflected, 'Reviewing literature in Day 2, I knew more communicative teaching methods; I am more confident now to teach creatively'.

In Day 3, the trainees' teaching competence and confidence increased, as did their understanding of communicative language teaching. They described many communicative activities such as employing language function and fluency-based and accuracy-based activities in task-based language learning. Additionally, they discussed methods to overcome the challenges of teaching adolescent learners in large classes. and discussed their adaptation in classroom.

These changes in the trainees' confidence and competence are explained below, along with the factors that were identified as contributing to the trainees' increased willingness to participate.

\section{Factors Contributing to the Improvement of Trainees' Confidence in Cycle 2}

The trainer and trainees identified several factors that contributed to the trainees' improvement of teaching English. These factors increased the trainees' confidence and competence to teach English creatively, and - as noted by most trainees - they increased their willingness to find 
alternatives in classroom practices and teach differently. Similar to Cycle 1, these factors were a stimulating training environment, a positive atmosphere, collaboration, authentic activities and interactive training, and a learner-centered approach.

\section{RECOMMENDATIONS}

\section{The Need for Ongoing Action Research in Training Rooms}

Action research in Saudi training courses is minimal. Training-based research would provide an added benefit for training supervisors, stakeholders and researchers. Providing Saudi trainers the opportunity to network and reflect on MCE outcomes would result in the sharing of innovative ideas and up-to-date resources. Trainers would be better prepared to make informed training decisions and cater to the individual needs of their trainees (Creswell, 2013). They would be more informed about effective training strategies that are research based and could contribute to the improvement of professional development. An added outcome of trainer reflection would be trainees' investigations of their own competency as English teachers. With improved trainees' confidence and competence to teach English, trainees would benefit from more effective demonstrations and trainer modelling. In classroom practices, Saudi teachers rarely reflect on their teaching practices because of the predetermined nature of teaching content from textbook-they follow a prescriptive curriculum. Providing participant teachers the opportunity to interact and reflect on their teaching would result in the sharing of innovative ideas and up-to-date resources.

With MCE results, Saudi education stakeholders would benefit from participating in systematic collection and analysis of data to inform change in training courses, make improvements and solve problems relating to the teaching of English in Saudi classrooms. In order for research to be sustained, effective and beneficial to trainers and trainees as well, there must be support from stakeholder. This action research study was unique because trainees had engaged in this research. It was a new experience for trainees, and they valued the opportunity to share their views and experiences in order to improve the English classroom.

\section{The Need for Supportive Training Environments}

This study highlights the difference that a supportive, collaborative training environment can have for trainees' engagement and participation. By creating a stimulating learning environment through MCE, positive attitudes replaced negative attitudes. The trainees had fun interacting with others, and enjoyment and enthusiasm replaced anxiety, doubt and hesitation. Over time, the trainees felt comfortable and confident discussing solutions for their difficulties in classroom as suggested by Cook Hirai et al (2010).

Employing interactive training methods contributed to the improvement of the trainees' engagement in the training practices. The adoption of an interactive pedagogy in MCE is completely different from the typical training sessions, and, in this action research study, it resulted in an increase in trainees' positive attitudes towards English training courses. The trainees had more opportunities to listen, engage with and apply their developing skills in interacting with and learning from their colleagues. 
Trusting and supportive relationships between the trainer and trainees were essential for MCE. In typical Saudi training room, trainers remain distant as a result of cultural and social respect. MCE emphasises the need for Saudi trainers to consider their roles to reduce trainees' anxiety to encourage increased participation, positive attitudes and elimination of fear. In such a context, trainees' confidence and participation in communicative training is enhanced.

\section{The Need for collaboration}

Trainees' participation in discussions improved when they had sufficient time of speaking freely about their challenges in classroom (Meise, 2011). In typical Saudi training course, trainees have limited opportunities to speak up about their challenges of teaching English using a prescribed textbook. It became apparent in MCE that, by increasing the opportunities for trainees to speak about their difficulties in classrooms with their colleagues, the trainees' selfperceptions as major component in the educational process were enhanced, and their sense of responsibility increased. It is recommended that all stakeholders have the opportunity from time to time to discuss the challenges in FLE and suggest solutions.

With MCE, the classroom environment was encouraging as trainees were expected to speak, even in Arabic to express themselves. Generally, in free discussions with supervisors, trainers avoid speaking about their challenges in classroom as they will not be taken seriously. With $\mathrm{MCE}$, these strategies are ineffective and contrary to assisting trainees develop their confidence and competence to teach differently.

\section{The Need for Authentic Communicative Activities}

Trainees in MCE found that when the communicative activities were comprehensible and designed to accommodate their needs, acknowledged their challenges and respect their beliefs, they showed greater willingness to participate in the activities as suggested by Coyne, Kame'enui \& Carnine (2010). Consequently, they became more confident and their competence increased in terms of employing alternatives in classrooms.

Most English training courses focus on grammatically perfect conversation. In contrast, MCE focuses on encouraging trainees' confidence and competence in teaching English through the use of authentic and relevant communication as suggested by Gass and Mackey (2012).

According to the trainees, their preferences were for the three themes of MCE because they were based on authentic, interactive activities, and were relevant to the trainees as indicated by Norris (2011). MCE is based on the themes of the first three stages of research: Theme 1 'identifying the problem', Theme 2 'reviewing literature' and Theme 3 'develop a plan'. The trainees were encouraged upon the completion of MCE to implement the following two stages of research 'implement the plan' and 'evaluate the outcomes' at their classrooms.

Trainees 35, 87, 94 and 112 reflected in the trainees' reflections survey that now they understand that when content is meaningful, students are more likely to take risks and try, rather than succumb to the obstacles of insufficient or inadequate input.

In MCE, session plans are flexible and can be adjusted to accommodate all learners, 
irrespective of their levels of competence. While the training activities move in a logical sequence and are planned, the trainer is expected to reflect and adjust training to ensure trainees are given adequate assistance or challenged as required. With MCE, it was found that planning added a layer of assurance for the trainer and contributed to the trainees' confidence as noted by Larsen-Freeman and Anderson (2011). Planning allowed the trainer time to think about options and alternatives to deal with issues that may arise. From my own perspective, when conducting MCE, I realized that the more confident I became with the training and content, the more confident were the trainees.

Being well planned and conscious of time use was critical to the success of MCE. Establishing a training routine was necessary to allow the training activities to move smoothly as recommended by Bermel (2008). Each activity of MCE was practiced over suitable period to allow more opportunities to participate and more time to adjust.

\section{The Need for a Learner-centered Approach}

When implementing a learner-centered approach in MCE, a significant change occurred in the role of the trainer and trainees, compared to the typical training experience of the trainees noted by Doyle (2011). The trainer role changed from that of the dominator and director of training to the facilitator and supporter of the trainees' independent learning. The role of the trainees changed dramatically from passive responders to active and independent learners. It was found that, through increased opportunities for trainees' participation, their personalities blossomed and they willingly shared their feelings, insights and understandings with the trainer and each other as recommended by Lamb and Reinders (2008).

The learner-centered approach is an uncommon experience for Saudi trainees, but it is recommended by this study. The trainees adjusted how they participated and the frequency with which they engaged with each other. The MCE activities motivated them to work in groups, as well as seek individual solutions. This subsequently promoted the trainees' competence and confidence to participate in the English training courses.

In a learning-centered classroom, trainees' roles are central and active as highlighted by Griffiths (2008). Trainees have ample opportunity to discuss ideas, form opinions, solve problems, plan and design communicative classroom activities, reflecting on learning strategies, and participate in assessments. The trainees gradually decreased their dependence on the trainer as they became autonomous learners who were more responsible and self-regulating. This positively enhanced the trainees' personalities and motivated independence in learning. The trainees' participation was greater and the trainer support was less. The use of English increased and the use of Arabic decreased.

This study recommends that Saudi trainers be encouraged with support to explore the advantages of a learner-centered approach. When trainees are given more opportunities to be independent and to think and reflect on their learning, their confidence to participate is enhanced (Cullen, Harris \& Hill, 2012). In this study, learning-centered activities, directed group discussions and participation in group work assisted the trainees to overcome their sensitivity to be open to new ideas, and decreased their fear of trying alternative ideas in 
education.

When considering a shift to a learner-centered approach in English training course, it is necessary for Saudi trainers to consider their multiple roles. Their roles change before, during and after implementing the communicative activities. Before introducing the activity, the trainer's role is that of tutor, organizer, encourager and supporter. During the activity, the trainer's role is that of participant, resource, prompter, observer and facilitator. After the speaking activity, the trainer's role is that of assessor and provider of feedback. The trainer's role is always helpful and, when necessary, the trainer gives gentle correction to assist trainees with misunderstandings and hesitations.

\section{The Need for a Systemic Approach to Overcome Current Constraints}

The continued development of English training courses, such as MCE, in MoE training departments and centers is constrained primarily because most training supervisors lack the immediate contact to the classroom practices in regular basis. In addition, according to AlHazmi (2003), most English teachers are not qualified to teach English because they lack subject knowledge, language proficiency, and necessary skills in English foreign language education. Furthermore, pre-service and in-service education for EFL supervisors and teachers education programs is unplanned and inconsistent. In order to address this primary concern, this study recommends that a systematic approach to improving pre-service and in-service education for EFL Trainee education programs be instigated.

Saudi education is dominated by a textbook-driven curriculum that prescribes what is taught and how it is taught. The MoE plans, establishes and develops educational resources. It is mandatory for all schools at all levels to use the same methods of instruction, textbooks, evaluation techniques and educational policy. As is evident from this action research study, trainees exhibit a range of EL proficiencies and, while some trainees require assistance, others need to be challenged. Moreover, the trainees' high levels of participation and interaction in this study indicated that group work and interesting activities promoted a higher level of learning than did passively following a textbook and completing a workbook. Thus, this study recommends that a review of the English curriculum and prescribed textbook be undertaken to enable accommodation of the range of student needs, interests and learning styles.

At a system level, improvement in the English Foreign language education requires collaboration between all stakeholders, including teachers, supervisors, researchers, curriculum specialists, program managers and administrators (Minichiello \& Kottler, 2010). A systemwide research agenda in effective English foreign language education is paramount, and the extension of MCE as a possible model to be adopted by other training supervisors is highly recommended.

\section{CONCLUSION}

This action research study investigated the introduction, implementation and evaluation of MCE of a training course-Meaningful Communication in English (MCE) - designed for English teachers at Saudi public schools. It investigated the influence of the theme-based 
activities of MCE on trainees' confidence and competence to teach differently.

Saudi public schools aim to educate learners to use English in real-life communication. Parents desire this and students who pursue further academic studies beyond school require this. However, large numbers of Saudi high school students graduate lacking the confidence to speak English. This disappointing outcome demands the exploration and development of English speaking training courses, such as MCE, to incorporate communicative and interactive pedagogies, rather than trainer-centered, worksheet-based instruction.

The course, MCE, emphasises that a learner-centered approach contributes positively to trainees' confidence and linguistic competence. The trainees engaged with authentic activities in a stimulating and supportive learning environment. The trainees adjusted to their changing roles from passive learners to active trainee, and reaped the benefits of increased participation and engagement. They spoke in English with each other and the Trainee. They experimented when they were unsure, rather than being fearful or anxious. They developed positive attitudes towards teaching English, and made connections between English and their lives both within and outside the classroom, while respecting and adhering to their cultural and religious values.

An English training course that embraces active engagement in teaching English is groundbreaking in the Saudi context. This study has the potential to change classroom English speaking practices, and the MCE ideas are now available to be trialled in public schools in KSA.

MCE and the findings of the study will contribute to improved classroom practices and inform policymakers about teaching spoken English in Saudi classrooms. Engaging, interactive and learner-centered courses, such as MCE, are necessary if the commitment to producing confident and competent English teachers is to be realized. This study highlights the need for ongoing research and evaluation of current instruction in English-speaking classrooms in Saudi public schools.

\section{REFERENCES}

Ahmad, A., Sahak, R. (2009). Teacher-student attachment and teachers' attitudes towards work. Journal Pendidik dan Pendidikan, 24, pp. 55-71.

Al-Abdallay, M. (2010). TOEFL is the first obstacle that faces scholarships and reveals the weakness of the foreign language education in Saudi Arabia. Alwatan Newspapers. Retrieved on 15 October 2010 from

http://www.alwatan.com.sa/Nation/News_Detail.aspx?ArticleID=22890\&CategoryID=3

Al-Bluey, F. (2016). Weak English learning outcomes. Where is the imbalance? Al-jazirah Newspapers. Retrieved on 20 January 2016 from http://www.aljazirah.com/2016/20160120/ar9.htm

Al-Hazmi, S. (2003). EFL Trainee preparation programs in Saudi Arabia: Trends and challenges. TESOL Quarterly, 341-344.

Al Qahtani, M., (2013), Administrative reform and its Role in the Development of Saudi 
Arabia. Riyadh: King Fahd National Library.

Al-Qurashi, K. (2002). Saudi trainers to learn how to teach English. Arab News. Retrieved on 5 April 2009 from http://arabnews.com/Article.asp?ID=17638\&ArY=2002\&ArM=8\&ArD=10

Al-Seghayer, K. (2011). English Teaching in Saudi Arabia: Status, Issues, and Challenges. Riyadh, KSA: King Fahd National Library.

Al-Seghayer, K. (2014). The Actuality, Inefficiency, and Needs of EFL Trainee-Preparation Programs in Saudi Arabia. International Journal of Applied Linguistics \& English Literature, 3 (1), 143-151. http://dx.doi.org/15.7575/aiac.ijalel.v.3n.1p.143

Al-Sha lan, Th. (2010). The number of general education trainees raised up to 5 million. Dar Al Hayat Newspapers. Retrieved on 10 March 2011 from http://international.daralhayat.com/ksaarticle/205350

Al-Sunbul, A., Al-Kataib, M., Metwally, M. \& Abduljawad, N. (2008). The system of education in the Kingdom of Saudi Arabia (in Arabic). Riyadh, KSA: Dar Al-Kheraijy.

Al-Tabinawi, W. (2007), Strategies for Change Management in Public Organisations. Cairo: Cairo University.

Akkary-Karami, R. (2014). Facing the Challenges of Educational Reform in the Arab World. Journal of Educational Change,15, 179-202.

Arani, M. (2004). Policy of education for the 21stcentury in developed and developing countries: Focus on Japan and Persian Gulf Region. Journal of International Cooperation Studies, 11 (3), 101-130.

Ary, D., Jacobs, L., Razavieh, A. \& Sorensen, C. (2010). Introduction to research in education. Belmont, CA: Wadsworth Cengage Learning.

Bailey, K., Curtis, A. \& Nunan, D. (2001). Pursuing professional development: The self as source. Boston, MA: Heinle \& Heinle.

Bermel, J. (2008). Implementing a curriculum innovation with sustainability: A case from Upstate New York. (Unpublished doctoral thesis). University of New York, Buffalo.

Birks, M. \& Mills, J. (2011). Grounded theory: A practical guide. Los Angeles, CA: SAGE Publications.

Charmaz, K. (2006). Constructing grounded theory: A practical guide through qualitative analysis. Los Angeles, CA: SAGE Publications.

Cook Hirai, D., Borrego, I., Garza, E. \& Kloock, C. (2010). Academic language/literacy strategies for adolescents: A 'how to' manual for educators. New York, NY: Taylor \& Francis.

Corbin, J. \& Strauss, A. (2008). Basics of qualitative research. Los Angeles, CA: SAGE 
Publications.

Coyne, M., Kame'enui, E. \& Carnine, D. (2010). Effective teaching strategies: That accommodate diverse learners (4th ed.). Upper Saddle River, NJ: Pearson.

Creswell, J. (2013). Qualitative inquiry and research design: Choosing among five approaches. Thousand Oaks, CA: SAGE Publication.

Cullen, R., Harris, M. \& Hill, R. (2012). The learner-centered curriculum: Design and implementation. San Francisco, CA: John Wiley \& Sons.

Doyle, T. (2011). Learner-centered teaching: Putting the research on learning into practice. Sterling, Virginia: Stylus Publishing.

Dukhayil, A. (2002). Higher education outputs and their compatibility with future development requirements in the Kingdom. Riyadh, KSA: KFUPM, Future vision of Saudi Arabia.

Gass, S. \& Mackey, A. (2012). The Routledge handbook of second language acquisition. New York, NY: Routledge.

Griffiths, C. (2008). Lessons from good language learners. Cambridge, UK: Cambridge University Press.

Kingdom of Saudi Arabia Vision 2030. (2016). Retrieved on 25 April 2020from http://vision2030.gov.sa/en

Lamb, T. \& Reinders, H. (2008). Learner and Trainee autonomy: Concepts, realities, and responses. Philadelphia, PA: John Benjamins.

Larsen-Freeman, D. \& Anderson, M. (2011). Techniques and principles in language teaching (3rd ed.). Oxford, UK: Oxford University Press.

Lichtman, M. (2010). Understanding and Evaluating Qualitative Educational Research. California: SAGE Publications.

Meise, J. (2011). First and second language acquisition: Parallels and differences. Cambridge, UK: Cambridge University Press.

Minichiello, V. \& Kottler, J. (2010). Qualitative journeys: Student and mentor experiences with research. London, UK: SAGE Publication.

Nather, E. (2017). An Integrated Program to Promote the Confidence of Saudi Public School Students in Speaking English. Academic Research International Journal, 8 (3), 65-74.

Nather, E. (2020). Saudi Students and Teachers' Strategies and Beliefs in Learning and Teaching English in Saudi Arabia. Advances in Social Sciences Research Journal, 7 (9), 664672.

Norris, J. (2011). Task-based teaching and testing. In M. Long \& C. Doughty (Eds.), The handbook of language teaching (pp. 578-594). Malden, MA: Wiley-Blackwell. 
Reid, W. \& Walker, D. (2012). Case studies in curriculum change: Great Britain and the United States. New York, NY: Routledge \& Kegan Paul.

Saudi MoE. (2005a). Tatweer program. Retrieved on 4 September 2009 from http://www.moe.gov.sa/Pages/Default.aspx

Saudi MoE. (2005b). The executive summary of the Ministry of Education ten-year plan 2004-2014 (in Arabic). Riyadh, KSA: Author.

Saudi MoE. (2013). The National Strategy for Public Education Development in the Kingdom (in Arabic). Riyadh, KSA: Author.

Saudi MoHE. (2010). Higher education in Saudi Arabia (in Arabic). Retrieved on 25 July 2010 from http://www.mohe.gov.sa/ar/default.aspx

Sager, A. (2004). Reform in Saudi Arabia: Current Challenges \& Feasible Solutions. Dubai: Gulf Research Centre.

Stringer, E. (2007). Action research in education. New Jersey: Pearson Education.

Stronge, J. (2007). Qualities of effective teachers (2nd ed.). Alexandria, Virginia: Association for Supervision and Curriculum Development.

Tatweer. (2010). Retrieved on 30 October 2010 from

http://www.tatweer.edu.sa/En/AboutUs/Pages/Overview.aspx

\section{Copyright Disclaimer}

Copyright reserved by the author(s).

This article is an open-access article distributed under the terms and conditions of the Creative Commons Attribution license (http://creativecommons.org/licenses/by/3.0/). 